NBER WORKING PAPER SERIES

\author{
CAPITAL STRUCTURE CHOICE \\ WHEN MANAGERS ARE IN CONTROL: \\ ENTRENCHMENT VERSUS EFFICIENCY
}

Walter Novaes

Luigi Zingales

Working Paper 5384

\author{
NATIONAL BUREAU OF ECONOMIC RESEARCH \\ 1050 Massachusetts Avenue \\ Cambridge, MA 02138 \\ December 1995
}

We wish to thank Tarun Chordia, Doug Diamond, Paolo Fulghieri, Thomas Hemmer, Glenn Hubbard, Craig Lewis, Tony Marciano, Fausto Panunzi, Jim Poterba, Jeff Pontiff, Raghu Rajan, Ed Rice, Carlo Scarpa, Rob Vishny, and seminar participants at EPGE/FGV, Kellogg, the University of Washington, the NBER 1994 Summer Institute, and at the 1994 WFA meeting for their useful comments. The second author acknowledges financial support from the Center for Research in Security Prices. This paper is part of NBER's research program in Corporate Finance. Any opinions expressed are those of the authors and not those of the National Bureau of Economic Research.

() 1995 by Walter Novaes and Luigi Zingales. All rights reserved. Short sections of text, not to exceed two paragraphs, may be quoted without explicit permission provided that full credit, including $\odot$ notice, is given to the source. 


\title{
CAPITAL STRUCTURE CHOICE \\ WHEN MANAGERS ARE IN CONTROL: \\ ENTRENCHMENT VERSUS EFFICIENCY
}

\begin{abstract}
Recent capital structure theories have emphasized the role of debt in minimizing the agency costs that arise from the separation between ownership and control. In this paper we argue that capital structure choices themselves are affected by the same agency problem. We show that, in general, the shareholders' and the manager's capital structure choices differ not only in their levels, but also in their sensitivities to the cost of financial distress and taxes. We argue that only the managerial perspective can explain why firms are generally reluctant to issue equity, why they issue it only following a stock price run-up, and why Corporate America recently deleveraged under the same tax system that supposedly generated the increase in leverage in the 1980s.
\end{abstract}

Walter Novaes

Department of Economics, DJ-10

University of Washington

Seattle, WA 98195
Luigi Zingales

Graduate School of Business

University of Chicago

1101 East 58th Street

Chicago, IL 60637

and NBER 
Recent capital structure theories (e.g., Grossman and Hart (1982), Jensen (1986), Stulz (1990), and Hart and Moore (1995)) have emphasized the role played by debt in reducing agency conflicts between managers and shareholders. Debt increases efficiency because it prevents managers from financing unprofitable projects. At the same time, debt may also block some profitable investment opportunities. The optimal capital structure, then, represents the ex ante efficient trade off between these costs and benefits.

These theories, though, leave unresolved the issue of who will choose such an optimal capital structure. They emphasize the role of debt in reducing agency problems between managers and shareholders, but they ignore that the choice of debt itself is subject to an agency problem. Short of claiming that the optimal capital structure is designed once and for all by the initial founders, these theories have to rely on self-interested managers to implement the optimal financing decisions. This fact raises two questions. First, how can we expect a manager to voluntarily increase the firm's leverage to decrease her own discretion? Second, even admitting that managers might be forced to use debt, why should we expect their choices to coincide with the ex ante optimal ones?

The first question has been addressed by Harris and Raviv (1988), Stulz (1988), and especially Zwiebel (1992). All these papers show how a takeover threat forces a manager to increase leverage. In particular, Zwiebel (1992) shows this might happen even if the takeover pressure is permanent. However, none of these studies analyze the possible divergence between a manager's choice under a takeover threat and the ex ante optimal capital structure. Hart and Moore (1995) conjecture that "the thrust of our analysis applies also to the case where management chooses financial structure to maximize its own welfare". The purpose of this paper is to illumine the conditions under which this claim could fail, and to investigate the sources and the implications of such a divergence between the two notions of optimality.

To achieve this objective we build a model which jointly considers the two main disciplinary mechanisms: debt and the corporate control market. In this framework, we derive the optimal capital structure both from a manager's and from a shareholders' point of view.

Our characterization of the shareholders' point of view is of independent interest, because, unlike existing models which analyze the ex ante choice of debt as a discipline device, we 
explicitly model the effects of debt not only on the likelihood of bankruptcy but also on the likelihood of a takeover.

Our characterization of the managers' point of view is similar to Zwiebel (1992), in that a manager maximizes her job tenure, which is threatened by two possible events: bankruptcy and takeovers. The occurrence of both these events is affected by the capital structure in place. In our model, though, the manager realizes that the use of debt may crowd out the effectiveness of takeovers and uses this crowding out effect in a way that maximizes her own entrenchment. This creates a distortion in the manager's capital structure choice.

We show that, in general, the shareholders and the manager's capital structure choices differ. Depending on a company's relative performance and on the pressure from the corporate control market, the manager may underlever or overlever her company with respect to the ex ante optimal shareholders' choice. More importantly, the two choices differ not only in their levels, but also in their sensitivities to the cost of financial distress and taxes. For instance, while the efficiency approach has standard predictions on the effects of taxes, the entrenchment approach predicts an asymmetric and variable sensitivity of capital structure choice to tax incentives. In sum, in a world where managers control capital structure decisions, Hart and Moore's (1995) conjecture does not necessarily hold.

Our questioning of this conjecture highlights the importance of examining the capital structure decisions from a manager's perspective. This perspective was strongly advocated by Donaldson (1969) more than twenty five years ago, but its full implications have never been worked out. It has generally been identified with the simple idea that managers underlever their companies for fear of the personal costs of bankruptcy. This risk aversion explanation, however, is far from satisfactory. It cannot explain why risk-averse managers are reluctant to issue equity and why the same risk-averse managers who generally underlever their companies chose to undertake major leverage recapitalizations in the 1980s.

By contrast, our paper fully develops the entrenchment approach as an alternative way to look at capital structure decisions. We show that our formulation of the entrenchment approach is able to explain why and when managers are reluctant to issue equity. At the same time, it provides further and novel insights on other dimensions of the capital structure 
decisions, like the choice between public and private debt and the choice of debt covenants. Finally, this approach is able to explain the early 1990s deleverage of Corporate America under the same tax system that allegedly generated the increase in leverage in the late $1980 \mathrm{~s}$.

The remainder of the paper proceeds as follows. Section 1 describes the basic structure of the model. Section 2 derives the ex ante optimal capital structure. Section 3 derives the optimal capital structure from a manager's point of view and compares it with the ex ante optimal. Section 4 describes how the manager's choice responds to tax subsidies for debt and equity. Section 5 presents some relevant extensions. Section 6 discusses the empirical implications of our model. Finally, section 7 concludes with a discussion of the policy implications of a model based on managerial entrenchment.

\section{General Framework}

Our interest is to compare the capital structure decisions made by self interested managers with those that shareholders would make. Therefore, we consider a firm run by a manager whose interests are not perfectly aligned with shareholders. We model this conflict of interests by assuming that the manager wants to retain her control position, even when she is not the best person for the job. ${ }^{1}$ For simplicity, we abstract from other sources of conflicts of interest between managers and shareholders (like investment policy or effort) and focus only on the most radical version of it: who should run the firm. Let $s \in \Re^{n}$ be a vector of attributes summarizing the incumbent manager's ability and let $s^{\star}$ be the optimal manager's type. Then we are interested in analyzing the cases where $s \neq s^{\star}$.

We restrict our analysis to one production period. The value of the firm at the end of this period consists of two factors. The first one, $y_{1}(\theta)$, captures the effects on the firm's value of the uncertainty during the period. $\theta$ represents a productivity shock uniformly distributed over the interval $[0,1]$. To simplify our analysis we shall assume that the effect of the productivity shock is linear, that is, $y_{1}(\theta)=\theta$. The second component, $y_{2}(s)$, reflects the value of the firm as

\footnotetext{
${ }^{1}$ The tension between a CEO with private benefits and shareholders who want the best person to run the business is the same as in Grossman and Hart (1988), Harris and Raviv (1988) and (1989), Stulz (1988), and Israel (1992).
} 
a function of the quality of the incumbent manager at the end of the period. Suppose that the firm is auctioned off with the incumbent manager. Then, $y_{2}(s)$ represents the "continuation value" of the firm if the $s$-type manager is still in place at the end of the period, while $y_{2}\left(s^{\star}\right)$ is the firm's value when the optimal manager has been put in place.

By assuming risk neutrality and a zero discount rate, the value of a firm where the type-s manager retains control is given by

$$
V(s)=E\left[y_{1}(\theta)\right]+y_{2}(s)
$$

By contrast, if before the end of the period the type- $s$ manager is dismissed and replaced with the optimal manager, the value of the firm is

$$
V\left(s^{\star}\right)=E\left[y_{1}(\theta)\right]+y_{2}\left(s^{\star}\right)
$$

The incumbent manager can be unseated in two ways: either the company enters bankruptcy and the manager is automatically dismissed, or shareholders coordinate to force the manager to step down. Regardless of how the incumbent manager is dismissed, we assume that the optimal type of manager is chosen to run the firm afterwards.

\subsection{The working of the corporate control market}

Shareholders are dispersed, therefore we assume that they can force the manager to step down only by paying a transaction cost $c$. The firing of the manager can be interpreted as a takeover, a proxy fight or some other form of shareholders' activism. For simplicity, in the rest of the paper we shall call a "takeover" any corporate control initiative, and a "raider" the leader of the control initiative. However, it is worth emphasizing that our framework is not restricted to the takeover case.

We assume that an inefficient manager is replaced if and only if it is profitable to do so, that is,

$$
S^{\star}-S \geq c
$$


where $S^{\star}$ is the company's equity value under the best possible manager and $S$ is the company's equity value under the current management.

To decide whether to undertake a takeover, a raider must compare $S^{\star}-S$ with $c$. We assume that $c$ is exogenous and known by the raider, the manager, and shareholders. Therefore, we focus on the increase in a target's equity value.

Note that equation (1) corresponds to assuming that shareholders cannot free ride on the improvement implemented by the raider. Moreover, we also assume that the market for corporate control is perfectly competitive. As a result, takeovers will be provided "at cost" whenever they are profitable. In practice, the corporate control market is probably not perfectly competitive, and takeovers may not occur even if they create value because the raider cannot appropriate enough of the takeover gains (see Grossman and Hart, 1980). Therefore, our assumptions on the market for corporate control are not chosen for realism, but to emphasize that distortions in capital structure choices arise even in this idealized world. As we shall show in section 5 , introducing more realistic features in the working of the corporate control market will only strengthen our results.

If the capital structure is such that there is no probability of default, then the left hand side of equation (1) corresponds to

$$
S^{\star}-S=y_{2}\left(s^{\star}\right)-y_{2}(s)
$$

Let's define $G(s) \equiv y_{2}\left(s^{\star}\right)-y_{2}(s)$, then a takeover will occur if and only if

$$
G(s) \geq c
$$

\subsection{The working of bankruptcy}

If at the end of the period the value of the firm under the incumbent management falls below the face value of the debt, then the company defaults and creditors take control of the company. We assume that in bankruptcy creditors replace the inefficient manager with 
the optimal one. ${ }^{2}$ Unfortunately, default is not a costless disentrenchment device. If the company goes into bankruptcy, then a fraction $\lambda \in(0,1)$ of $y_{1}(\theta)$ is lost. This is consistent with interpreting $y_{1}(\theta)$ as the current cash flow and $y_{2}(s)$ as the continuation value. We also assume that $G(s)<\lambda^{3}$

\subsection{The interaction between the two mechanisms}

The effects of leverage on the likelihood of a takeover depends on how a debt with face value $D$ changes the post-takeover increase in the company's equity value $\left(S^{\star}-S\right) .{ }^{4}$ Let us define $\theta_{D}$ as the lowest realization of the productivity shock such that the company does not default under the incumbent manager. Formally, this corresponds to

$$
\theta_{D}= \begin{cases}0 & \text { if } D<y_{1}(0)+y_{2}(s) \\ \text { solves } y_{1}\left(\theta_{D}\right)+y_{2}(s)=D & D \in\left[y_{1}(0)+y_{2}(s), y_{1}(1)+y_{2}(s)\right] \\ 1 & \text { if } D>y_{1}(1)+y_{2}(s)\end{cases}
$$

The firm's equity value without a takeover, then, is

$$
S(D)=\int_{0}^{\theta_{D}}\left[\operatorname{Max}\left\{y_{1}(\theta)-\lambda y_{1}(\theta)+y_{2}\left(s^{\star}\right)-D, 0\right\}\right] d \theta+\int_{\theta_{D}}^{1}\left[y_{1}(\theta)+y_{2}(s)-D\right] d \theta
$$

The first term captures the change in the firm's equity value when the incumbent cannot repay the debt. In these events, the company defaults and its value is reduced by the cost of financial distress $\lambda y_{1}(\theta)$. However, thanks to default, the incumbent is replaced and the

\footnotetext{
${ }^{2}$ This assumption is not as obvious as one might think. Creditors might be dispersed and they might face some of the same problems of shareholders. Nevertheless, the existing bankruptcy procedures are supposed to facilitate creditors' coordination. Furthermore, our assumption is without loss of generality because the value loss produced by a possible lack of creditors' coordination can be easily incorporated into the cost of financial distress.

${ }^{3}$ If $G(s) \geq \lambda$, then bankruptcy always increases the firm's value. We do not analyze this extreme case of inefficient entrenchment.

${ }^{4}$ We define $D$ as the face value of debt minus the amount of cash on hand. As we will discuss in section 6 this corresponds to interpret any equity issue as a corresponding debt reduction.
} 
"continuation" payoff is then $y_{2}\left(s^{\star}\right) .^{5}$ The second term shows the equity value when the company does not default and the manager stays in control.

If the incumbent manager is replaced by a takeover, then, efficiency is enhanced and, under the same debt level, the set of bankruptcy states will skrink. Therefore, we can define $\theta_{D}^{*}$ as the minimum value of $\theta$ such that default does not occur if the manager is replaced by a takeover. Formally,

$$
\theta_{D}^{\star}= \begin{cases}0 & \text { if } D<y_{1}(0)+y_{2}\left(s^{\star}\right) \\ \text { solves } y_{1}\left(\theta_{D}^{\star}\right)+y_{2}\left(s^{\star}\right)=D & D \in\left[y_{1}(0)+y_{2}\left(s^{\star}\right), y_{1}(1)+y_{2}\left(s^{\star}\right)\right] \\ 1 & \text { if } D>y_{1}(1)+y_{2}\left(s^{\star}\right)\end{cases}
$$

This definition allows us to write the firm's equity value in the case of a takeover as

$$
S^{\star}(D)=\int_{0}^{\theta_{D}^{*}} 0 d \theta+\int_{\theta_{D}^{*}}^{1}\left[y_{1}(\theta)+y_{2}\left(s^{\star}\right)-D\right] d \theta .
$$

Subtracting (4) from (5) and noting that $\theta_{D}^{\star} \leq \theta_{D}$ we can write the increase in equity value due to a takeover as

$$
\int_{\theta_{D}}^{1}\left[y_{2}\left(s^{\star}\right)-y_{2}(s)\right] d \theta+\int_{\theta_{D}^{\star}}^{\theta_{D}}\left[y_{1}(\theta)+y_{2}\left(s^{\star}\right)-D-\operatorname{Max}\left\{(1-\lambda) y_{1}(\theta)+y_{2}\left(s^{\star}\right)-D, 0\right\}\right] d \theta
$$

Let's define $\tilde{\theta}_{D}$ as the minimum realization of the productivity shock such that, in the absence of a takeover, shareholders receive some payments after bankruptcy. It is easy to see that, for $D$ belonging to $\left[(1-\lambda) y_{1}(0)+y_{2}\left(s^{\star}\right),(1-\lambda) y_{1}(1)+y_{2}\left(s^{\star}\right)\right], \tilde{\theta}_{D}$ is the minimum

\footnotetext{
${ }^{5}$ Because of the gains produced by replacing the managers, it is possible that, after default, the company can pay debtholders in full. Consistent with the bankruptcy law, shareholders receive any surplus left after paying the creditors.
} 
between $\theta_{D}$ and the solution of the following equation: ${ }^{6}$

$$
(1-\lambda) y_{1}\left(\tilde{\theta}_{D}\right)+y_{2}\left(s^{\star}\right)=D
$$

If $D<(1-\lambda) y_{1}(0)+y_{2}\left(s^{\star}\right)$, we set $\tilde{\theta}_{D}=0$. Likewise, we set $\tilde{\theta}_{D}=\theta_{D}$ if $D>(1-\lambda) y_{1}(1)+y_{2}\left(s^{\star}\right)$.

Then, after using the fact that $G(s) \equiv y_{2}\left(s^{\star}\right)-y_{2}(s)$, equation (6) can be rewritten as

$$
\Delta S(D)=\int_{\theta_{D}}^{1} G(s) d \theta+\int_{\theta_{D}^{\star}}^{\tilde{\theta}_{D}}\left[y_{1}(\theta)+y_{2}\left(s^{\star}\right)-D\right] d \theta+\int_{\tilde{\theta}_{D}}^{\theta_{D}} \lambda y_{1}(\theta) d \theta
$$

Equation (8) summarizes the three ways in which debt affects the profitability of a takeover. The first term shows that an increase in debt (and so an increase in $\theta_{D}$ ) reduces the profitability of a takeover by delivering the replacement gains in the bankruptcy states. This is what we call the crowding out effect of debt. The second term illustrates what was pointed out by Israel (1991): the existence of risky debt transfers some of the takeover gains from the raider to the target debtholders. This effect has been shown to be empirically relevant by Billet (1995).

Note that these two effects create a potential conflict of interests between the manager and shareholders in the choice of the optimal level of debt. Because the manager is interested in minimizing the probability of being replaced, she might inefficiently increase debt to use these two effects to decrease the profitability of a takeover. ${ }^{7}$

The third effect is the increase in equity value that comes with the lower probability of bankruptcy. By increasing efficiency, the raider reduces the probability of bankruptcy, and hence, saves part of the expected cost of financial distress. However, debtholders may bear some of the expected cost of financial distress. As a consequence, the last term of equation (8) is not the entire reduction in the expected cost of financial distress, but only the reduction

\footnotetext{
${ }^{6}$ For $D \in\left[(1-\lambda) y_{1}(0)+y_{2}\left(s^{\star}\right),(1-\lambda) y_{1}(1)+y_{2}\left(s^{\star}\right)\right]$, creditors are fully paid for states of nature above some cut-off point. If this cut-off is smaller than $\theta_{D}$, then so will be $\tilde{\theta}_{D}$. Otherwise, $\tilde{\theta}_{D}$ is equal to $\theta_{D}$, meaning that the probability that the creditors will be fully paid conditioned on bankruptcy is 1 .

${ }^{7}$ Here we implicitly assumed that the existing debt cannot be renegotiated. Otherwise, the raider and the creditors should enter in an agreement to reduce the face value of the debt to an amount that allows the value enhancing takeover. However, the manager can make it difficult for a raider to renegotiate the company's debt by choosing public debt over private debt. Indeed, as we shall show in section 6.3 , under a takeover pressure, the manager has the incentive to make any debt renegotiation more difficult.
} 
that would be borne by equityholders.

For future reference it is useful to establish the following result:

Lemma 1 The equity gain from a takeover, $\Delta S(D)$, is decreasing in $D$, with strict monotonicity for debt levels that the raider can pay with positive probability.

Proof: See Appendix.

Lemma 1 simply states that the equityholders stand to gain less from a takeover as the face value of debt increases. In other words, the first two (negative) effects of debt on the profitability of a takeover overcome the third one.

\subsection{The timing of the events}

Figure 1 summarizes the sequence of events and the payoffs in our model. At time 0 the capital structure is chosen either by the initial shareholders or by the incumbent manager. Whenever debt is issued, the proceeds are distributed to shareholders as dividends. If a takeover remains profitable after the change in the capital structure, then a raider takes over at time 1 and the manager is replaced. Otherwise, the manager remains in power at least until time 2. At this time, the industry-wide shock occurs, affecting the final payoff through $y_{1}(\theta)$. At time 3 the final payoffs are realized and the debt becomes due. If the company defaults, then the incumbent manager is replaced and the "continuation payoff" is $y_{2}\left(s^{\star}\right)$. Otherwise, the original manager stays in control and the "continuation payoff" is $y_{2}(s)$.

Figure 1: Sequence of events within the production period

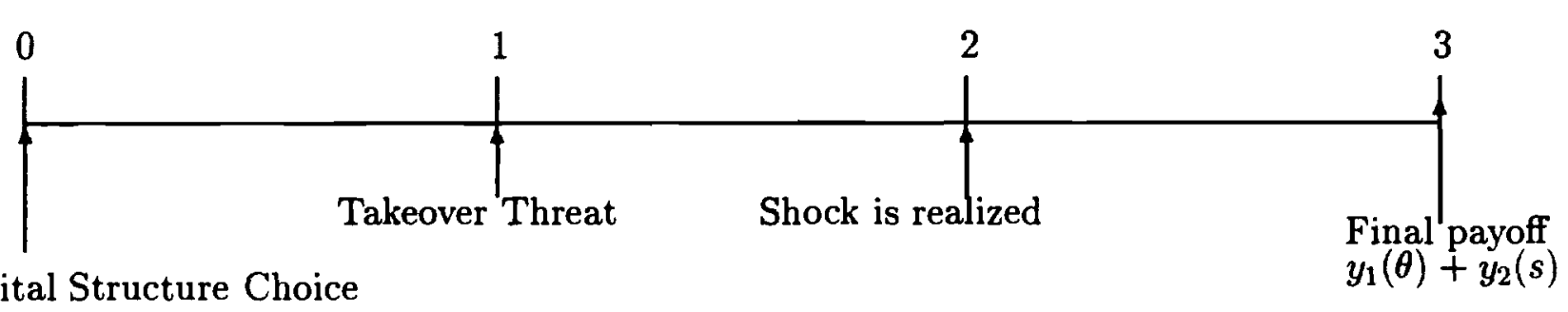




\section{The Value Maximizing Level of Debt}

In this section we compute the capital structure that initial shareholders would like to choose had they had the power and the ability to do so. In particular, we assume that they perfectly anticipate the type of manager who will be running the company in the future. In this context, one can think of the shareholders' capital structure decision as being a choice of the least expensive way of replacing inefficient managers: bankruptcy, takeover or a combination of the two.

We start by assuming that bankruptcy is the only disentrenchment device available, and we later move to the case in which takeovers are possible. Initial shareholders internalize all the costs and benefits of debt. Therefore, they choose the value of debt in order to maximize the firm's value:

$$
\max _{\theta D \in[0,1]} V\left(\theta_{D}\right)=\int_{0}^{\theta_{D}}\left[(1-\lambda) \theta+y_{2}(s)+G(s)\right] d \theta+\int_{\theta_{D}}^{1}\left[\theta+y_{2}(s)\right] d \theta
$$

where we used the fact that $y_{1}(\theta)=\theta$. The first integral is the firm's expected value conditioned on default. Default triggers the replacement of the management with the consequent gain $G(s)$, but it also costs the firm some financial distress $(\lambda \theta)$. The second integral is the value of the firm when there is no default.

The necessary condition (which in this case is also sufficient) for an interior maximum is

$$
G(s)-\lambda \theta_{D}=0
$$

It follows that the optimal level of debt triggers bankruptcy in all the states where $G(s)>\lambda \theta$ (that is the marginal replacement gain is larger than the marginal cost of financial distress). Note that if $G(s) \geq \lambda$ then the optimal level of debt will induce bankruptcy with probability one. This is why we restricted our analysis to the more interesting case where $G(s)<\lambda$.

It then follows 
Lemma 2 The ex ante optimal debt level in the absence of takeovers is

$$
D^{o}=\frac{G(s)}{\lambda}+y_{2}(s)
$$

Although our framework of analysis is somewhat different, $D^{o}$ corresponds to the results obtained by Stulz (1990) and Hart and Moore (1995). Consistent with them, the optimal debt does not fully eliminate all agency costs. In fact, when $\theta \geq \frac{G(s)}{\lambda}$ the inefficient manager remains in charge and this implies that shareholders will not receive $G(s)$. Furthermore, even when the manager is replaced, the company has to incur some cost of financial distress.

We summarize the expected cost of using debt as a disentrenchment strategy as

$$
C_{D}=\lambda E\left[\theta \mid \theta<\theta_{D}\right]+\left(1-\theta_{D}\right) G(s)
$$

Note that $C_{D}$ includes both the direct cost of financial distress (first term) and the opportunity cost of not replacing the manager in some states of nature (second term).

Let's now see how the optimal debt changes when we introduce the possibility of takeovers. If $G(s)<$ c, then there is no change because takeovers are unprofitable, and so they are not a viable alternative. Consider $G(s) \geq c$. In this case takeovers are profitable in the absence of debt. Thus, initial shareholders have to decide whether they want to rely on takeovers, debt, or a combination of the two to disentrench the manager. However, because there is no uncertainty about the gains and costs of a takeover, the cost of takeovers will be either less than the expected cost of debt, wherein debt is unnecessary, or larger than the expected cost of debt, wherein shareholders should use debt to discipline the manager. Since there is no doubt ex ante as to which method has the lower expected cost, and since allowing takeovers eliminates any role for debt, it will always be optimal to use one method or the other, but never both in combination. Therefore, we can think of the shareholders' problem as a choice between using only debt or only takeovers to replace the manager. If they choose debt as the disentrenchment device, there is no reason for not using it in an optimal way (i.e., $D=D^{o}$ ). Hence, the solution of the shareholders' problem boils down to comparing $C_{D^{\circ}}$ (i.e., $C_{D}$ computed at the optimal debt level $D^{o}$ ) with the takeover cost $c$. 
If $C_{D^{\circ}} \geq c$, then takeovers are more efficient than bankruptcy in replacing the manager. In this case the initial shareholders would like to minimize their interference with the working of the corporate control market. As a result, they choose any level of debt that does not block a takeover and which never forces the raider into bankruptcy.

If $C_{D^{\circ}}<c$, then debt is a less expensive disentrenchment device than takeovers (net advantage of debt $G(s)-C_{D^{\circ}}$ bigger than the net advantage of takeovers $G(s)-c$ ). In this case initial shareholders rely only on debt. This is achieved by setting the debt level equal to $D^{\circ}$. Note that, with this level of debt, a takeover could increase the value of equity by at most $C_{D^{\circ}}$. Since $C_{D^{\circ}}<c$, takeovers are not profitable and the use of bankruptcy alone is the optimal disentrenchment device.

The following proposition summarizes the optimal debt choice from the shareholders' point of view.

Proposition 1 Let's define $D^{1}$ as the maximum level of debt that never forces the raider into bankruptcy (i.e., $D^{1}=y_{1}(0)+y_{2}\left(s^{\star}\right)$ ), $D^{2}$ as the maximum level of debt that does not block a takeover (i.e., $D^{2}=\max \{D: \Delta S(D) \geq c\}$ ), and $D^{s}$ as the minimum between the two $\left(D^{s}=\min \left\{D^{1}, D^{2}\right\}\right)$. Then, the debt level that maximizes shareholders' value is given by

$$
D^{\star}= \begin{cases}{\left[0, D^{s}\right]} & \text { if } c<\min \left\{G, C_{D^{\circ}}\right\} \\ \frac{G(s)}{\lambda}+y_{2}(s) & \text { otherwise }\end{cases}
$$

where $C_{D^{\circ}}$ is defined by equation (11), with $D=D^{o}=\frac{G(s)}{\lambda}+y_{2}(s)$.

As the next corollary shows, the comparative statics on the ex ante optimal leverage is quite standard:

Corollary 1 The ex ante optimal debt level

a) decreases with the cost of financial distress $\lambda$,

b) increases with the takeover cost $c$,

c) generically increases with the replacement gain $G(s)$.

Proof: See Appendix. 
As expected, the shareholders' optimal debt decreases with the cost of financial distress. This happens because the increase in the relative cost of an instrument (in this case debt) induces initial shareholders to use less of it. The same intuition applies to the comparative static with respect to $c$. An increase in the cost of takeovers induces a substitution towards debt as a disentrenchment device. The third result is only slightly less straightforward. The total cost of debt $C_{D}$ is composed of a combination of the cost of financial distress and the opportunity cost of not replacing the manager. An increase in the replacement gain will push the optimal debt to a higher level to ensure that the higher replacement gain is lost in fewer states of nature.

\section{The Manager's Capital Structure Choice}

The manager's objective is to maximize her tenure. Thus, she minimizes the probability of being replaced either by a takeover or by creditors in default. This corresponds to minimizing the probability of bankruptcy conditioned on surviving the takeover threat. ${ }^{8}$

$$
\min _{\{D\}} \operatorname{Prob}\left\{y_{1}(\theta)+y_{2}(s)<D\right\}
$$

$$
\text { s.t. } \Delta S(D)<c,
$$

where $\Delta S(D)$ is the post-takeover increase in equity value as defined in equation (8).

The objective function is the probability of bankruptcy for debt level $D$. Equation (12) represents the main constraint on the manager's choice: a takeover must be unprofitable at the optimal debt level.

The manager's problem is very simple to solve when there is no real takeover pressure, that is, $G(s)<c$. In such case, an optimal debt level from the manager's point of view simply

\footnotetext{
${ }^{8}$ In this context takeovers will always be avoided. However, this is just a feature of the simplifying assumption on the nature of takeover costs. As we shall show in section 5, takeovers can occur in equilibrium once we introduce some uncertainty on the costs of the raider.
} 
minimizes the probability of bankruptcy. Therefore, any debt that the company can pay with probability 1 under the incumbent is optimal. Formally,

$$
D^{\star \star}=\left[0, y_{2}(s)\right]
$$

Solving the manager's problem is not so easy when the manager is under a real takeover pressure. Here, blocking a takeover requires some risk of bankruptcy. In principle, one might conjecture that debt cannot block takeovers when the replacement gain is very high or the takeover cost is very low. However, Lemma 3 below shows that there is always a sufficiently large debt that blocks a takeover.

Lemma 3 The managers can always block a takeover by choosing a debt level equal to

$$
\bar{D}=1+y_{2}\left(s^{\star}\right)
$$

This level of debt guarantees that the value of equity will always be zero, even after a takeover. As a result, $\Delta S(\bar{D})<c$. However, $\bar{D}$ also leads the incumbent into bankruptcy with probability one. Therefore, before opting to such an extremely high leverage the incumbent manager would be interested in checking if the takeover can be blocked by a debt level that she can pay in some state of nature.

Define $D^{r}$ as the set of risky debt levels that the incumbent can pay in some state of nature. It is easy to see that $D^{r}$ is the interval $\left(y_{2}(s), 1+y_{2}(s)\right]$. If $\Delta S(D)<c$ for some $D$ in $D^{r}$, then $1+y_{2}\left(s^{\star}\right)$ cannot be optimal because there is another debt, that the incumbent can pay in some state of nature, which also blocks the takeover. In this case the optimal debt level is $D^{m} \equiv \theta^{m}+y_{2}(s)$, where $D^{m}$ is the minimum debt in $D^{r}$ that satisfies $\Delta S(D)<c .^{9}$

Finally, if $\Delta S(D) \geq c$ for any $D \in D^{r}$, then the manager will have to accept bankruptcy with probability 1 to block the takeover. We do not gain any insight by characterizing the set of debt levels that block the takeover at the cost of bankruptcy with probability 1 for the

\footnotetext{
${ }^{9}$ Technically, the minimum debt level in $D^{r}$ that satisfies $\Delta S(D)<c$ might not exist because the set $\left\{D \in D^{r}: \Delta S(D)<c\right\}$ is not closed. Therefore, the reader should interpret $D^{m}$ as $\tilde{D}+\epsilon$, where $\tilde{D}$ solves $\Delta S(\tilde{D})=c$ and $\epsilon>0$ is as small as needed.
} 
incumbent. Hence, in this case we simply take $1+y_{2}\left(s^{\star}\right)$ as the optimal debt level.

Proposition 2 below summarizes the optimal debt choice from the manager's point of view.

Proposition 2 The optimal debt level for the manager equals

$$
D^{\star \star}= \begin{cases}{\left[0, y_{2}(s)\right]} & \text { if } G(s)<c \\ \theta^{m}+y_{2}(s) & \text { if } G(s) \geq c \text { and }\left\{D \in D^{r}: \Delta S(D)<c\right\} \neq \emptyset \\ 1+y_{2}\left(s^{\star}\right) & \text { otherwise, }\end{cases}
$$

where $D^{r}=\left(y_{2}(s), 1+y_{2}(s)\right]$, and $\theta^{m}+y_{2}(s)=\tilde{D}+\epsilon$ with $\Delta S(\tilde{D})=c$ and $\epsilon>0$ as small as necessary.

Having identified the manager's preferred solution, we can now derive the corresponding comparative statics.

Corollary 2 The optimal debt level from the manager's point of view

a) increases with the cost of financial distress $\lambda$,

b) decreases with the takeover cost $c$,

c) increases with the replacement gain $G(s)$.

Proof: See Appendix.

The most surprising result is the first one. A theory based on entrenchment predicts an increase in leverage when the cost of financial distress increases. The underlying logic is the following: the cost of financial distress represents a subsidy to the raider, who, by replacing the manager, not only gets $G(s)$, but also captures the reduction in the expected costs of financial distress (equal to the last term in equation (8)). As a result, ceteris paribus a higher cost of financial distress increases the profitability of a takeover. The manager's objective is to survive at the helm of the company, so she will respond to the increased takeover pressure in the only way she has to block a takeover: increasing debt.

The entrenchment approach also differs from the efficiency one in its predictions on the effects a change in takeover costs will have on leverage. In the entrenchment approach, an increase in the takeover cost decreases the takeover pressure and, as a result, reduces the 
manager's need for debt. In the efficiency approach, an increase in the cost of takeovers increases the optimality of using bankruptcy as a disentrenchment device. Therefore, the efficiency approach predicts that leverage increases with the takeover cost.

The third result coincides with the comparative statics of Corollary 1. Both the efficient and the entrenchment solutions predict an increase in leverage when the replacement gain increases. One possible measure of the replacement gain is the differential performance with respect to the industry mean: the lower the relative performance (for instance, profitability) the higher the replacement gain. Under both regimes, thus, more profitable companies should be less highly leveraged. It does not come as a surprise, then, that the negative relationship between leverage and profitability is one of the most widely established empirical correlations (e.g., Rajan and Zingales, 1995).

\subsection{A comparison between the two solutions}

The efficient and the entrenchment choices of debt differ not only in their sensitivity to certain parameters, but in their optimal levels as well. Let's use as a benchmark the shareholders' optimal solution (which happens to be also the socially efficient one):

Proposition 3 The manager underlevers the company if $c>G(s)$ or $c \leq G(s)$ and $c>$ $\Delta S\left(\frac{G(s)}{\lambda}+y_{2}(s)\right)$. She overlevers if $c<\Delta S\left(\frac{G(s)}{\lambda}+y_{2}(s)\right)$ or $c \leq G(s)<C_{D^{o}}$.

Proof: It follows from a comparison of the results obtained in Propositions 1 and 2, and $\Delta S(D)$ decreasing with $D$.

Underleverage arises when the takeover pressure does not exist (i.e., $c>G(s)$ ), or it is not strong enough to induce the manager to the optimal leverage (i.e., $c>\Delta S\left(\frac{G(s)}{\lambda}+y_{2}(s)\right)$ ). These cases are likely to happen when the takeover cost is high or when the incumbent manager has a high relative performance. Overleverage occurs when the takeover pressure is so strong that it forces the manager to lever up beyond the efficient level (i.e., $c<\Delta S\left(\frac{G(s)}{\lambda}+y_{2}(s)\right)$ ), or when takeovers are cheaper than debt as a disentrenchment device and the manager uses risky debt to block the takeover. The first reason for overleverage is similar to the rationale behind the use of a scorched earth strategy as an antitakeover device. The second one is 
more original and it is directly related to the agency problem in the choice of the appropriate disentrenchment instrument. The manager chooses debt even if this is a more inefficient disentrenchment device, because it allows her to stay in control in some states of nature.

\section{Debt and Taxes}

\subsection{Tax subsidy for debt}

The purpose of this section is to analyze what are the effect of taxes on capital structure choice in the two approaches. We model the tax subsidy for debt as a rebate equal to $t$ times the total payments (and not just the interest payments) made to debtholders. This assumption captures in a one period model the features of the debt tax shield in an infinite horizon company. As a consequence we have that the present value of the debt tax shield, $D T S(D)$, is given by

$$
D T S(D)=t B(D)
$$

where $B(D)$ is the market value of a debt with a face value equal to $D$.

The initial shareholders understand the tax benefits of debt, and they will maximize the value of the firm plus the value of the debt tax shield. As we show in the appendix, the solution of this program delivers standard results on the effects of taxes.

Corollary 3 The optimal leverage from the initial shareholders' perspective increases whenever a tax subsidy for debt is introduced.

Proof: See Appendix.

To derive the manager's optimal debt in a world with taxes we first have to show how the introduction of taxes changes the value of the company for the raiders. Then we proceed as before, looking for the minimum level of debt that makes the takeover unprofitable. 


\subsubsection{The optimal trade-off between tax benefits and financial distress in the absence of agency costs}

After the takeover, the best manager will be running the company and the raider sets the capital structure by weighting the tax benefit of debt and the cost of financial distress. In other words, when the agency problem has been resolved, our model collapses to the traditional trade-off theory of capital structure.

Lemma 4 The debt level that optimally trades-off financial distress and tax savings is $D^{T}=$

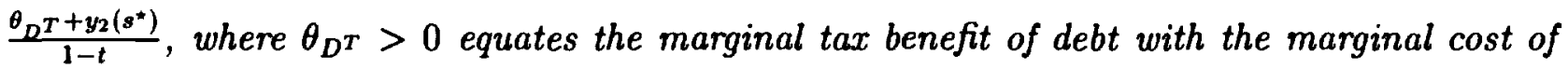
financial distress:

$$
\lambda \theta_{D^{T}}=t\left(1-\theta_{D^{T}}\right)
$$

Proof: See Appendix.

We are now ready to discuss the effects of a tax subsidy for debt on the manager's capital structure choice. We divide the analysis into two cases. First we consider a manager who, in the absence of the tax subsidy, is insulated from the market for corporate control. Then we look at a manager who is under takeover pressure even in the absence of a tax subsidy for debt.

\subsubsection{The effects of a tax subsidy when the takeover pressure is low}

Suppose that, in the absence of taxes, the manager is insulated from the market for corporate control (i.e. $G(s)<c$ ). We shall argue that, in this case, there exists a cut-off that determines whether the tax subsidy will have any effect. If the tax subsidy is below this cut-off, then the manager will be isolated from the takeover pressure even under the pre-existing capital structure with only riskless debt. By contrast, if the tax subsidy is above the cut-off, the manager is then forced to lever up to a risky level of debt.

To compute this cut-off it is sufficient to compare the value of equity before and after a takeover in the presence of a tax subsidy for debt. In the absence of a takeover, the equity value of the firm having the highest possible level of riskless debt outstanding $\bar{D}^{T}$ is 


$$
S=E[\theta]+y_{2}(s)-(1-t) \bar{D}^{T}
$$

where $\bar{D}^{T}=\frac{y_{2}(s)}{1-t} \cdot{ }^{10}$

Once a raider buys out the company's equity and repays the debt, she can set up the debt level, $\frac{\theta_{D} T+y_{2}\left(s^{*}\right)}{1-t}$, that optimally trades-off tax benefits and financial distress. ${ }^{11}$ Thus, the firm's equity value after a takeover is

$$
\begin{gathered}
S^{\star}=\theta_{D^{T}}\left[E\left[(1-\lambda) \theta \mid \theta<\theta_{D^{T}}\right]+y_{2}\left(s^{\star}\right)+t\left(\frac{E\left[(1-\lambda) \theta \mid \theta<\theta_{D^{T}}\right]+y_{2}\left(s^{\star}\right)}{1-t}\right)\right]+ \\
\left(1-\theta_{D^{T}}\right)\left[E\left[\theta \mid \theta \geq \theta_{D^{T}}\right]+y_{2}\left(s^{\star}\right)+t\left(\frac{\theta_{D^{T}}+y_{2}\left(s^{\star}\right)}{1-t}\right)\right]-\bar{D}^{T} .
\end{gathered}
$$

Subtracting $S$ from $S^{\star}$ and evaluating the expectations, we obtain the increase in the firm's value due to a takeover

$$
G(s)+\left\{\frac{t}{1-t}\left[\int_{0}^{\theta_{D^{T}}}(1-\lambda) \theta d \theta+\left(1-\theta_{D^{T}}\right)\left(\theta_{D^{T}}\right)+G(s)\right]-\lambda \frac{\theta_{D^{T}}^{2}}{2}\right\}
$$

Equation (16) tells us that in the presence of taxes the raider not only captures the replacement gain $(G(s))$, but also the optimal tax benefit of leverage, that the incumbent manager was not fully exploiting for fear of her personal costs in bankruptcy. The second term precisely represents the gain from optimally levering up the company, which is formed by the increase in tax savings less the expected cost of financial distress. Let's define as $R(t, \lambda, \theta, G(s))$ this

\footnotetext{
${ }^{10}$ The maximum safe debt can be obtained as follows. The face value of the debt, $D$, must be equal to the firm's cash-flow in the worst state of nature. We can divide this cash-flow in two components. The first one is the cash-flow in the absence of the tax subsidy: $\theta+y_{2}(s)$, which is equal to $y_{2}(s)$ in the worst state of nature $(\theta=0)$. The second component is the tax subsidy, which is equal to $t D$ when the debt is safe. Therefore the maximum safe debt $D$ solves $D=y_{2}(s)+t D \Rightarrow D=\frac{y_{2}(a)}{1-t}$.

${ }^{11}$ Note that a raider fully internalizes the company's debt value because she bears any cost of bankruptcy through the interest rate. Therefore, she has the correct incentives to choose the debt level that optimally trades-off tax benefits and bankruptcy costs.
} 
net tax benefit of debt. Thus, the takeover is profitable if and only if

$$
G(s)+R\left(t, \lambda, \theta_{D^{T}}, G(s)\right) \geq c
$$

Note that $R(t, \lambda, 0, G(s))=\frac{t G(s)}{1-t}>0$. Hence, the expected gain from the optimal debt, $R\left(t, \lambda, \theta_{D^{T}}, G(s)\right)$, must be strictly positive. In fact, the following proposition proves that for each $c, \lambda$, and $G(s)$ there exists a level of tax subsidy, $\tilde{t}(c, \lambda, G(s))$, such that the manager otherwise isolated from the corporate control pressure is forced to issue risky debt if and only if $t \geq \tilde{t}(c, \lambda, G(s))$.

Proposition 4 Suppose that $G(s)<c$. For any takeover cost, replacement gain, and cost of financial distress there exists a tax subsidy for debt, $\tilde{t}(c, \lambda, G(s)) \in\left(0,1-\frac{G(s)}{c}\right)$, such that a takeover of a company with no risky debt is profitable if and only if $t \geq \tilde{t}(c, \lambda, G(s))$. Moreover, $\tilde{t}(c, \lambda, G(s))$ increases with $c$ and $\lambda$ and decreases with $G(s)$.

Proof: See Appendix

The comparative statics of Proposition (4) is quite intuitive. The cut-off, $\tilde{t}(c, \lambda, G(s))$, increases with $c$ because it is easier to block a costlier takeover. Likewise, an increase in $\lambda$ reduces the profits from levering up the company. Since riskless debt does not allow the incumbent to default, the increased cost of financial distress hurts only the raider. Finally, an increase in the replacement gain, $G(s)$, increases the profitability of a takeover. Therefore, a lower tax benefit is needed to induce a takeover.

Proposition (4) may shed some light on the recent changes in the leverage of Corporate America. In the 1980s, financial innovations like junk bonds significantly decreased the costs of a hostile takeover. In our model, this would be equivalent to a decrease in $c$ and, consequently, of $\tilde{t}(c, \lambda, G(s))$. Our conjecture is that this drop in $c$ pushed the actual tax subsidy beyond $\tilde{t}(c, \lambda, G(s))$ for many firms, forcing managers to increase leverage. On the other hand, antitakeover legislation in the late 1980 s increased $c$ and, thus, $\tilde{t}(c, \lambda, G(s))$. As a result, the actual tax subsidy went below $\tilde{t}(c, \lambda, G(s))$, and managers felt free to delever their companies. This might explain why Corporate America delevered under the same tax structure that generated the "overleverage" of the 1980s. 


\subsubsection{The effects of a tax subsidy when the takeover pressure is high}

We now study the effects of a tax subsidy for debt in the case that a takeover is profitable in the absence of any risky debt (i.e., $G(s) \geq c$ ).

In this case the effect of the tax subsidy for debt is more ambiguous. In fact, the tax subsidy adds a new source of profits to takeovers only if it is optimal for the raider to increase leverage beyond the level chosen by the manager. ${ }^{12}$ If so, a tax subsidy for debt forces the manager to lever up.

By contrast, when the incumbent manager is more highly leveraged than the raider would like to be, then the tax subsidy for debt decreases the takeover gains. Partially liberated from the takeover pressure, the incumbent manager can then afford to decrease the leverage. As a result, the introduction of a tax subsidy for debt will have the counterintuitive effect of decreasing the leverage of highly levered firms.

\subsection{Tax subsidy for equity}

In the previous subsection we showed that a sufficiently large subsidy for debt may force an otherwise entrenched manager to lever up. In this subsection we show that a tax subsidy for equity fails to induce the manager to decrease the leverage. Indeed, it can actually force her to increase leverage.

Consider a manager who would be fully entrenched in a tax neutral economy, that is $G(s)<c$. Now, introduce a subsidy that pays a percentage $t$ on a firm's equity value. If the manager stays with an all equity capital structure, then the firm's value under her control becomes $(1+t)\left(E\left[y_{1}(\theta)\right]+y_{2}(s)\right) \cdot{ }^{13}$ On the other hand, if the raider takes over the firm the equity value is $(1+t)\left(E\left[y_{1}(\theta)\right]+y_{2}\left(s^{\star}\right)\right)$. As usual, a takeover is profitable if and only if the increase in equity value is larger than the takeover cost, that is

\footnotetext{
${ }^{12}$ Note that level of leverage we are discussing uses the market value, not the face value of debt, because the value of the debt tax shield is a function of the market value of debt.

${ }^{13}$ Note that there is no reason for the manager to choose a riskless debt level different from zero because the all equity capital structure maximizes firm's value under the incumbent's control and minimizes the probability of bankruptcy.
} 


$$
(1+t) G(s) \geq c .
$$

If $(1+t) G(s)<c$, then the manager is still insulated from the market for corporate control despite the tax subsidy for equity, and she stays with an all equity capital structure. If $(1+t) G(s) \geq c$, then the tax subsidy for equity makes a takeover profitable under an all equity capital structure. The manager is forced to lever up.

Now consider the case where the manager is not entrenched in the absence of the subsidy, that is $G(s)>c$. Here, one could conjecture that the tax subsidy for equity might attenuate an overleverage. The following proposition proves that this conjecture is wrong:

Proposition 5 The introduction of a tax subsidy for equity increases the manager's optimal level of leverage.

Proof: See Appendix.

The intuition is straightforward. The manager under a takeover pressure chooses the minimum debt that blocks a takeover. The introduction of a tax subsidy for equity equal to $t$ increases the potential gains from a takeover by $t \Delta S(D)$ (i.e., the increase in the equity value produced by a takeover times the magnitude of the subsidy). Thus, after the introduction of the subsidy the manager sets a debt level that obtains

$$
(1+t) \Delta S(D)<c
$$

In other terms, the effect of a tax subsidy for equity is to decrease the effective cost of a takeover from $c$ to $\frac{c}{1+t}$. As we proved in Corollary 2 this has the effect of increasing debt.

In sum, our model identifies a fundamental asymmetry in the working of tax incentives when managers are in control. While a tax subsidy for debt induces managers to increase leverage, a tax subsidy for equity has the perverse effect of increasing rather than decreasing leverage. As a consequence, a differential taxation of debt and equity might be designed to address an underleverage problem, but it cannot be used to address an overleverage one. 


\section{Extensions}

\subsection{Alternative Means of Entrenchment}

In this paper we have focused on the capital structure choice as an entrenchment device. However, managers can entrench themselves in a variety of ways. They can invest in assets that are specific to them (Shleifer and Vishny, 1989), choose an organizational structure that makes them indispensable (Novaes and Zingales, 1995), or more simply they can introduce poison pills and antitakeover devices. The availability of these instruments might reduce or even eliminate the need for using debt as an entrenchment device. In such case, the manager would choose riskless debt, and the deviations from the shareholders' optimal capital structure would only be in the direction of underleverage.

However, there are two reasons why capital structure decisions might be relevant even after these other entrenchment devices are considered. First, entrenchment devices are more powerful when their antitakeover effects are less obvious. Whenever the conflict of interest behind a manager's decision is transparent, entrenchment decisions are likely to be stricken down by the court. By contrast, when the decision that entrenches the manager is a pure business decision (as financing is), the business judgment rule applies, that is, the court does not interfere. ${ }^{14}$

Furthermore, entrenchment devices do not come without costs and limits. If - for example - the choice of manager-specific assets introduces large inefficiencies, the overall effect on the likelihood of a takeover can be counterproductive..$^{15}$ In sum, if no instrument alone can completely isolate the manager, multiple ways of entrenching can be complementary rather than substitutes in reaching the manager's final goal.

\footnotetext{
${ }^{14}$ For instance, in the recent controversy about the excessive cash holding (low leverage) chosen by Chrysler's management, the Wall Street Journal (September 15, 1995) reports the following opinion of an analyst: "We are talking about subtleties and legitimate differences of opinion on how aggressively you run the company. I don't know if that's enough to change control".

${ }^{15}$ For an analysis of the consequences of this trade-off on a manager's ability to remain in power see Novaes and Zingales, (1995).
} 


\subsection{The market for corporate control is not perfectly competitive}

Thus far we have assumed that the corporate control market is perfectly competitive and that there is no free riding. Under these assumptions, the necessary and sufficient condition for takeovers to occur is $S^{\star}-S \geq c$. In this section we relax these assumptions.

As an alternative we assume that the raider can capture only a fraction $\phi$ of the equity gains that a takeover generates. This formulation captures two possible deviations from the benchmark case. The first one is that existing shareholders can free ride, but the raider is allowed to dilute a fraction $\phi$ of the efficiency gains. Alternatively, $\phi$ represents the fraction of gains a raider can get in a bargaining with the incumbent management.

From the manager's perspective the required change is minor. Takeovers will occur whenever

$$
\phi \Delta S(D) \geq c
$$

The manager's optimal solution picks the minimum level of debt such that $\phi \Delta S(D)<c$. However, this corresponds to the results obtained in Proposition 2, with a cost of takeover of $\frac{c}{\phi}>c$. In other words, the previous analysis carries through, and this renormalization has the effect of increasing the takeover costs.

By contrast, from the initial shareholders' perspective the assumption of a non competitive market modifies the cost of using takeovers as a disentrenchment device. The cost is no longer $c$, but is now $\phi \Delta S(D)$. An interesting aspect of this modification is that the cost of a takeover depends on the company's leverage. Previously, the initial shareholders were only interested in finding the least costly disentrenchment device. Now they should also care about minimizing the surplus of a potential raider. In other terms, we have superimposed to the framework of section 2 a surplus extraction problem similar to the one described in Israel (1991).

This change has no consequences if $C_{D^{\circ}} \leq c$. In this case the initial shareholders would prefer debt as a disentrenchment device even if they could extract all the raider's surplus. Therefore, the solution will still be $D=\frac{G(s)}{\lambda}+y_{2}(s)$. However, the joint use of takeovers and debt may be the best alternative when $C_{D^{\circ}}>c$. In this case, the initial shareholders would like to introduce risky debt to extract some of the takeover gains. 
Note that if the initial shareholders were only interested in minimizing the raider's surplus, then their solution would be almost equal to the manager's solution. The initial shareholders would choose $\phi \Delta S(D)=c$, still leaving an incentive for the raider to take over, while the managers would choose a slightly larger debt $(\phi \Delta S(D)=c-\epsilon)$ to make sure that the takeover would not happen. However, the initial shareholders are also concerned with the cost of financial distress. Therefore, shareholders' solution should favor less debt in the capital structure than the manager's solution.

In sum, relaxing the assumption that the market for corporate control is perfectly competitive has no substantial effect on the manager's solution and it has the effect of pushing the initial shareholders' solution closer to the manager's one.

\subsection{Stochastic takeover costs}

In our model takeovers never happen in equilibrium because the manager always prefers default rather than being ousted by a takeover. However, this unrealistic feature is a mere consequence of the assumption that the cost of a takeover is perfectly known by the manager at the time of the leverage decision. By introducing some uncertainty on the takeover cost we obtain a trade-off between the probability of a takeover and the probability of bankruptcy. With this extension, takeovers and bankruptcies can both occur in equilibrium. In this subsection, we sketch this result.

We assume that the takeover cost $c$ can take two values $\bar{c}$ and $\underline{c}$, with $\bar{c}>\underline{c}$. With probability $p>0$, takeover costs are high, $c=\bar{c}$, while with probability $1-p$ the takeover cost is low, $c=\underline{c}$.

We assume $G(s) \leq \bar{c}$ and $G(s) \geq c$. Hence the manager may be fully entrenched under a high takeover cost but not when the takeover cost is low. Moreover, we assume that the takeover can be blocked by a debt level that the incumbent can pay in some state of nature when the takeover cost is high. ${ }^{16}$

\footnotetext{
${ }^{10}$ Otherwise the takeover can never be blocked by a debt that the incumbent can pay in some state of nature. In this situation the manager faces no trade-off between takeover threat and bankruptcy, since the latter is the only alternative to survive a takeover.
} 
Although we assume that the takeover cost is not contractible, it is useful for expositional purposes to derive the capital structure that a manager would like to set had she had the ability to write a debt contract whose face value depends on the takeover cost.

The debt level that minimizes the probability of bankruptcy and blocks the takeover for a given $c$ is the optimal debt derived in Proposition 2. Calling $D(c)$ the optimal debt contingent on $c$, Corollary 2 allows us to write $D(\underline{c})>D(\bar{c})$.

Given that the manager cannot issue debt contingent on $c$, the optimal debt strategy (from the manager's perspective) is either to block the takeover for any $c$ or to block it only when the takeover cost is high. The choice between these two strategies depends on a trade-off between the probability of bankruptcy and the probability of a strong takeover pressure (low c).

Consistent with what we have assumed so far, the manager wants to remain in power as long as possible. Therefore, we say that the manager's utility is 1 if she is not replaced and zero if she is replaced. Call $\bar{\theta}$ the cut-off state for default with a debt level $\bar{D} \equiv D(\underline{c})$; that is, the incumbent defaults if and only if $\theta<\bar{\theta}$. Likewise, define $\underline{\theta}$ as the cut-off state for default with a debt level $\underline{D} \equiv D(\bar{c})$. Since $\bar{D}>\underline{D}$, we have $\bar{\theta}>\underline{\theta}$.

The manager's utility levels with debt levels $\bar{D}$ and $\underline{D}$ are

$$
\begin{gathered}
U(\bar{D})=(1-\bar{\theta})+\bar{\theta} 0=(1-\bar{\theta}) . \\
U(\underline{D})=p(1-\underline{\theta})+(1-p) 0=p(1-\underline{\theta}) .
\end{gathered}
$$

In words, the manager can block the takeover with $\bar{D}$ for any realization of the takeover cost. However, she remains in control only if there is no bankruptcy. So, her expected utility with $D=\bar{D}$ is equal to the probability of staying out of bankruptcy. For debt $\underline{D}$, the manager survives a takeover only if $c=\bar{c}$, which happens with probability $p$. Still, the manager hopes that $\theta \geq \underline{\theta}$, allowing her to survive bankruptcy. The manager should choose the lower debt level if and only if $U(\underline{D})>U(\bar{D})$. This happens when 


$$
p>\frac{1-\bar{\theta}}{1-\underline{\theta}} .
$$

The above condition is satisfied when the probability of a high takeover cost is larger than the ratio between the probability of avoiding bankruptcy respectively under a high and a low debt level. In such a case there is a positive probability of takeover even when the manager issues risky debt.

\section{The Efficiency versus the Entrenchment Approach}

Since Grossman and Hart (1982) a large body of literature derives predictions on the firm's financing decisions by adopting an ex ante-efficiency perspective. While this approach is generally cast in terms of an initial entrepreneur who seeks to maximize her firm's value, the conjecture is that its predictions are valid whenever an (unmodeled) outside pressure forces managers to choose a value maximizing debt level.

The most natural candidate to generate such a pressure is the corporate control market. Our model, however, shows that, depending on a company's relative performance and on the pressure from the corporate control market, the manager may underlever or overlever her company with respect to the efficient level. More importantly, the two choices differ not only in their predicted levels, but also in their sensitivities to taxes and costs of financial distress. For instance, while the efficiency approach predicts leverage to be positively related to the tax advantage of debt and negatively related to the tax advantage of equity, the entrenchment approach predicts an asymmetric and variable sensitivity of capital structure to tax incentives. Moreover, the sensitivity of leverage to tax subsidies is not constant through time and across companies, but is a function of a company's relative performance and the strength of the pressure from the corporate control market. Similarly, while the efficiency approach predicts a negative correlation between debt and costs of financial distress, the entrenchment approach predicts a positive one. 
In sum, our analysis shows that the corporate control market is not sufficient to guarantee that managers would make value maximizing capital structure decisions. This result, though, does not necessarily rule out the implications derived using the value maximizing approach. These might still hold if we accept one of the following two assumptions.

Capital structure choices might be efficient because they are chosen by the initial founders. This literal interpretation, though, requires that the initial founder be able to choose, once and for all, the optimal level of debt, either by specifying an entire menu of state contingent financial policies or by designing a system of incentives that will induce future management to make value maximizing choices. Corporate charters, however, do not contain such complex state contingent provisions about future financial policies. Similarly, the evidence about managerial incentive contracts (e.g., Jensen and Murphy, 1990) suggests that managers' incentives are not well aligned with value maximization.

Alternatively, one could argue that there are other outside forces - like product market competition - that induce the management to make value maximizing choices. A priori it is not obvious to us why these forces should work very differently from takeover pressure, and thus why they shouldn't generate the same distortions we pointed out in this latter case. We think that identifying these forces and understanding their working is an important step for future research.

At the current stage of knowledge, though, the managerial entrenchment approach to capital structure choice is a clearly credible alternative. Such a position is hardly new - it was strongly advocated by Donaldson (1969) more than twenty five years ago --, but it has not received due attention in the literature. It has generally been identified with the simple idea that managers underlever their companies for fear of the personal costs of bankruptcy. This simple risk aversion explanation, however, is incapable of explaining why managers are reluctant to issue equity (Donaldson, 1961) and why the same risk-averse managers chose to undertake major leverage recapitalization in the 1980s.

By contrast, in what follows we show that our formulation of the entrenchment approach provides a complete alternative to the efficiency approach, which is consistent with the major stylized facts on firms' financing choices and is able to explain other important dimensions of 
capital structure decisions.

\subsection{Equity Issues}

Since Donaldson (1961), it has been recognized that managers are reluctant to issue equity. More recently, Opler and Titman (1995) document that new equity issues are clustered after big run up in stock prices, while stock repurchases follow a decline in stock prices.

Agency-based models of capital structure are generally unable to account for the possibility of equity issues, let alone explain their patterns. All the existing models that regard debt as a discipline device fail to explain why managers do not issue equity to free themselves from this discipline. As long as the company is not bankrupt (i.e., equity has a positive value), managers can always raise new funds through an equity issue. ${ }^{17}$ Similarly, a simple risk aversion explanation is incapable of explaining why managers should not issue equity to minimize the probability of a default. Note that the usual Myers' (1977) argument (i.e., in the presence of a debt overhang existing shareholders are hurt by an equity issue) cannot be invoked here. If managers are more concerned about maximizing their own utility rather than shareholder's value - as agency models assume - then the loss incurred by existing shareholders should not be able to stop them from issuing equity to avoid a default. ${ }^{18}$ By contrast, our entrenchment model not only is robust to managers' ability to issue equity, but is also able to explain the timing of this decision.

First, the manager's optimal leverage, which we derived in Proposition 2, remains unchanged if we introduce the possibility managers can issue equity. In fact, in that proposition the face value of debt $D$ is defined net of any possible cash on hand. An equity issue, then,

\footnotetext{
${ }^{17}$ This can be easily seen through the following example. Suppose that the value of equity is $\$ 1$ dollar and that the debt overhang is so severe that any new fund raised will benefit only debtholders (so that the total amount of equity after the issue is still \$1). A manager can still raise an additional dollar of funds by issuing an extremely large number of shares. The claim of new shareholders will equal the proportion of new shares over the total number of shares times the value of equity. When the number of new shares goes to infinity, the new shareholders will appropriate the entire value of the outstanding equity (i.e., \$1) and, thus, will be willing to pay that much to underwrite the new shares.

${ }^{18}$ One could (legitimately) argue that there are other forces that prevent a manager from issuing equity when this hurts the existing shareholders. If these forces exist and are so relevant, though, they should be explicitly considered in the leverage decision
} 
can be interpreted as an increase in the amount of cash on hand and, thus, as a decrease in the debt level $D$. In other terms, our model explains why managers do not want to issue equity to free themselves from the discipline of debt even when they are allowed to do so. By issuing equity a manager would increase the profitability and, hence, the probability of a takeover. The same threat that forced her to leverage up, prevents her to issue equity. Therefore, our model is consistent with the fact, first observed by Donaldson (1961), that managers generally do not issue equity even if they can do so.

Second, the comparative statics derived in Corollary 2 provides some implications on when a firm is likely to issue equity and when to repurchase it. Suppose that a shock makes the incumbent manager especially valuable for the company. This represents good news for the company, which will experience a rise in stock price, but an even better news for the manager, who will become more entrenched thanks to the reduction in the replacement gains $G(s)$. The decrease in $G(s)$ reduces the debt level necessary to block a takeover. As a result, the incumbent manager - partially freed by the fear of a takeover - will want to deleverage the company by issuing equity in order to reduce the probability of a default. By contrast, when the replacement gains increase (and stock prices decline), the incumbent manager has to increase leverage (repurchase equity) to thwart a takeover. Therefore, our model is able to explain why equity issues are clustered after a big run up in stock prices, while stock repurchases follow a decline in stock prices (see Opler and Titman, 1995). ${ }^{19}$

Corollary 2 also links equity issues (repurchases) to a change in the costs of takeovers: when takeover costs decrease, the incumbent manager would like to increase leverage to thwart a takeover and may do that by repurchasing stock. On the other hand, when takeover costs increase, the takeover threat becomes weaker and the manager can reduce leverage by issuing equity. These predictions are consistent with the wave of stock repurchases in the mid-late 1980s (when the introduction of junk bonds reduced the takeovers costs) and with the wave

\footnotetext{
${ }^{19}$ Of course, an alternative explanation of this phenomenon is that managers try to exploit a market deviation from fundamentals. Our model allows to test these two alternatives. Mispricing is more likely to be an industry phenomenon and, thus, equity issues should more sensitive to industry-wide movements in stock prices. By contrast, changes in the replacement gains are more likely an idiosyncratic factor, and, thus, equity issues should be more sensitive to the industry-adjusted changes in stock prices.
} 
of equity issues in the early 1990s, following the demise of hostile takeovers.

\subsection{The Effect of Taxes}

In the efficiency approach it is difficult to explain why firms have such a small response to the tax advantage to debt. Myers (1984) claims that he does not know of any strong evidence in favor of a tax effect. Since then, some evidence in favor of a tax effect have been produced (e.g., Mackie-Mason (1991) and Graham (1995)). Nevertheless, the capital structure of companies like American Home Product still defies any efficiency rationale. At the time of the case (Mullins, 1981), AHP was a well diversified drug company with very little $R \& D$, very stable cash flow, and a very strong balance sheet (cash balance equal to $40 \%$ of net worth). No reasonable costs of financial distress can offset the tax advantage of at least some debt. Nevertheless, AHP was virtually debt free.

By contrast, our entrenchment model can easily account for such cases. As we have shown in section 4.1, companies will differ in their sensitivity to taxes as function of the intensity of outside pressure. For a given takeover cost, the better an incumbent manager is, the less she would be threatened by a takeover and feel compelled to increase debt in response to a tax advantage. In other words, it is exactly its strong record of profitability that isolates AHP from a possible takeover and makes it insensitive to a tax subsidy for debt. ${ }^{20}$ It is also consistent with our model the fact that AHP overruled its no debt policy in 1994, precisely when it was rumored to be a potential takeover target (Wall Street Journal, August, 3 1994).

\subsection{The Private versus Public Debt Choice}

Our entrenchment model also provides an alternative theory of the choice of the number of creditors. Bolton and Scharfstein (1992) study the ex ante optimal number of creditors from the point of view of initial shareholders. However, managers can easily change the composition of their liabilities. Therefore, it is interesting to derive a theory of the dispersion of debt claims

\footnotetext{
${ }^{20} \mathrm{~A}$ related point on the AHP case is mentioned by Vishny (1992). He emphasizes that the capital market discipline might not be enough to force the incumbent to realize the tax savings. We further elaborate that it is because incumbent managers are so good that tax savings alone cannot justify a takeover.
} 
from a manager's point of view.

Managers have a bias toward public debt because if a raider can easily renegotiate a firm's debt with its creditors, then the manager will never escape a takeover by increasing leverage. Every time an excessive level of debt blocks a takeover, a raider could obtain a concession from debtholders to pay for the takeover cost. Now, assume that the dispersion of creditors increases the raider's cost of renegotiating with creditors before a takeover. Then, the incumbent managers who issue debt to protect themselves against a takeover will prefer to distribute it among dispersed investors, so as to prevent the raider from renegotiating the debt.

Thus, our model predicts that firms facing a takeover threat (i.e., firms issuing risky debt) should prefer to issue public rather than private debt or to exchange their existing private debt for public ones. To this regard it is interesting to note that while corporate bonds represented just $25 \%$ of the debt financing of nonfinancial corporations in 1979 - when hostile takeovers were very rare, they became $50 \%$ of the total in 1988 , at the peak of the takeover activity (see Gertler and Hubbard, 1990).

Note also that the manager's choice of public debt in our model is purely self-interested, because the dispersion of creditors will increase the costs of renegotiation in financial distress, thus reducing the value of equity. Therefore, our model predicts that firms exchanging private for public debt should experience a reduction in the price of their stock. This is, indeed, what Gilson and Warner (1995) find, analyzing a sample of junk bond issuers. More interestingly, they find - consistent with our theory - that the abnormal return associated to the announcement of a debt exchange is negative only in the early-mid 1980s, when hostile takeovers were more likely and, thus, entrenchment was the more likely cause of that decision.

\subsection{Other Aspects of Corporate Debt}

There are other features of corporate debt that might increase the effectiveness of debt as an antitakeover device. For instance, if existing debtholders can be diluted by a leverage recapitalization undertaken by a raider, then debt has no effect in deterring a takeover, and 
it may actually provide a subsidy for a takeover. For this reason, it is in the interest of the manager to write covenants that protect debtholders against the possible dilution produced by subsequent debt issues. Such a covenant should require an acquirer to pay down all the existing debt in case of an acquisition. This type of covenant, quite common in the 1980s, is called a "poison put". The very name indicates the antitakeover purpose of this covenant.

An alternative way to protect public debtholders would be to make them senior. However, recall that the less risky public debt is, the less it serves the purpose of an antitakeover device. Therefore, it is in the interest of the manager to make the public debt junior (and so more risky), transforming the bondholders into the recipients of part of the takeover gains. By contrast, bank debt, which tends to be more concentrated, can well be made senior. In short, the entrenchment approach provides an explanation for the seniority structure of debt that is quite different from the existing efficiency-based arguments (see Rajan and Winton, 1995, Burkart, Gromb and Panunzi, 1995).

\section{Conclusions}

In this paper we construct a framework that enables us to analyze various dimensions of capital structure decisions under two alternative approaches: efficiency and entrenchment. We show that a pressure from the corporate control market is not enough to guarantee that managers' financing decisions coincide with the value maximizing ones. The predictions differ not only in the level of the optimal capital structure, but also in the sensitivities of debt to the cost of financial distress and taxes.

These results raise two important questions for future research. First, from a theoretical point of view it would be interesting to discover whether there are other forces, like product market competition or the need for new financing, that induce managers to choose a value maximizing level of debt. Second, from an empirical point of view, it would be interesting to establish whether actual financing decisions are more consistent with the efficiency or the entrenchment approach. To this extent, a contribution of our model is to derive a set of testable implications that might help distinguish empirically between the two theories. 
Discerning the correct approach to explaining firms' financing decisions has very important policy implications. For instance, if capital structure is chosen by shareholders to maximize the firm's value, then it is well known that any differential treatment in the taxation of debt and equity is distortionary. But if capital structure is chosen by managers in their own self interest, then a tax-advantage for debt might be welfare enhancing. We hope that our model might provide a conceptual framework to guide empirical research on this important topic. 


\section{Appendix}

Proof of Lemma 1:

We define $\theta_{D}, \theta_{D}^{\star}$, and $\tilde{\theta}_{D}$ as in the text. However, to facilitate the exposition, we say that $\theta_{D}>1$ when $D>1+y_{2}(s)$. By using the assumption that $y_{1}(\theta)=\theta$, we can write $\theta_{D}^{\star}$ and $\bar{\theta}_{D}$ as a function of $\theta_{D}$ :

$$
\theta_{D}^{\star}= \begin{cases}0 & \text { if } \theta_{D}<G(s) \\ \theta_{D}-G(s) & G(s) \leq \theta_{D} \leq 1 \\ \operatorname{Min}\left\{1, D-y_{2}\left(s^{\star}\right)\right\} & \text { otherwise. }\end{cases}
$$

and

$$
\tilde{\theta}_{D}= \begin{cases}0 & \text { if } \theta_{D}<G(s) \\ \frac{1}{1-\lambda}\left[\theta_{D}-G(s)\right] & G(s) \leq \theta_{D} \leq \frac{G(s)}{\lambda} \\ \operatorname{Min}\left\{1, \theta_{D}\right\} & \text { if } \theta_{D}>\frac{G(s)}{\lambda}\end{cases}
$$

We divide the analysis in four intervals as a function of the level of $\theta_{D}$.

1. If $\theta_{D} \in[0, G(s)]$, then equation (8) becomes

$$
\Delta S(D)=\int_{\theta_{D}}^{1} G(s) d \theta+\int_{0}^{\theta_{D}} \lambda \theta d \theta .
$$

Differentiating (19) with respect to $\theta_{D}$ yields

$$
\frac{\partial \Delta S(D)}{\partial \theta_{D}}=-G(s)+\lambda \theta_{D},
$$

which is always negative for $\theta_{D}<G(s)$.

2. If $\theta_{D} \in\left(G(s), \frac{G(s)}{\lambda}\right]$, then equation (8) becomes

$$
\Delta S(D)=\int_{\theta_{D}}^{1} G(s) d \theta+\int_{\theta_{D}-G}^{\frac{1}{1-\lambda}\left[\theta_{D}-G\right]}\left[\theta+G(s)-\theta_{D}\right] d \theta+\int_{\frac{1}{1-\lambda}\left[\theta_{D}-G\right]}^{\theta_{D}} \lambda \theta d \theta
$$

Differentiating (21) with respect to $\theta_{D}$ yields

$$
\frac{\partial \Delta S(D)}{\partial \theta_{D}}=-G(s)+\frac{1}{1-\lambda}\left[\frac{\theta_{D}}{1-\lambda}-\frac{G(s)}{1-\lambda}+G(s)-\theta_{D}\right]-\int_{\theta_{D}-G}^{\frac{1}{1-\lambda}\left[\theta_{D}-G\right]} d \theta+\lambda \theta_{D}-\frac{\lambda}{(1-\lambda)^{2}}\left[\theta_{D}-G\right] .
$$

Simplifying, it becomes

$$
=-G(s)+\lambda \theta_{D}-\frac{\lambda}{1-\lambda}\left[\theta_{D}-G(s)\right] .
$$

This expression is negative if and only if

$$
\theta_{D}>\frac{2 \lambda-1}{\lambda^{2}} G(s) .
$$

This is satisfied because $\theta_{D}>G(s)$ in this interval and $\frac{2 \lambda-1}{\lambda^{2}}$ is increasing in $\lambda \in[0,1]$ and it reaches a maximum equal to 1 at $\lambda=1$.

3. If $\theta_{D} \in\left[\frac{G(\rho)}{\lambda}, 1\right]$, then equation (8) becomes

$$
\Delta S(D)=\int_{\theta_{D}}^{1} G(s) d \theta+\int_{\theta_{D}-G}^{\theta_{D}}\left[\theta+G(s)-\theta_{D}\right] d \theta
$$


Differentiating (25) with respect to $\theta_{D}$ yields

$$
\frac{\partial \Delta S(D)}{\partial \theta_{D}}=-\int_{\theta_{D}-G(\theta)}^{\theta_{D}} d \theta<0
$$

4. If $\theta_{D}>1$ and $\theta^{\star}=1$, then equation (8) becomes $\Delta S(D)=0$. If $\theta^{\star}<1$, then equation (8) becomes

$$
\Delta S(D)=\int_{D-y_{2}\left(s^{*}\right)}^{1}\left[\theta+y_{2}\left(s^{\star}\right)-D\right] d \theta
$$

whose derivative with respect to $D$ is $-\int_{D-y_{2}\left(a^{*}\right)}^{1} d \theta<0$.

\section{Proof of Corollary 1:}

- $\frac{\partial D}{\partial \lambda} \leq 0$. Consider first a change in $\lambda$ that does not shift $D^{\star}$ from $D^{\circ}$ to $\left[0, D^{*}\right]$ or vice versa. Of course, $\lambda$ does not affect $D^{\star}$ when the optimal choice is safe debt $\left(\left[0, D^{\star}\right]\right)$. On the other hand, it easy to see that $\frac{\partial D^{\circ}}{\partial \lambda}<0$ when $D^{\star}=D^{\circ}=\frac{G(\theta)}{\lambda}+y_{2}(s)$. Now consider changes in $\lambda$ that shift $D^{\star}$ from $D^{\circ}$ to $\left[0, D^{*}\right]$ or vice versa. An increase in $\lambda$ increases $C_{D}$, therefore at most it shifts $D^{\star}$ from $D^{\circ}$ to $\left[0, D^{\circ}\right]$. This implies a decrease in the optimal debt level because $\Delta S\left(D^{\circ}\right)<c$ and $\Delta S(D) \geq c$ for any $D \in\left[0, D^{*}\right]$. The same argument applies when $\lambda$ decreases. At most, it shifts $D^{\star}$ from from $\left[0, D^{*}\right]$ to $D^{\circ}$. This implies an increase in the optimal debt level.

- $\frac{\partial D}{\partial c} \geq 0$. If $D^{\star}=\left[0, D^{\star}\right]$ was optimal before and it remains optimal afterwards, then an increase in the takeover cost has no effect. The same is true if $D^{\star}=D^{\circ}$ before and after. In such case, takeovers are not used as a disentrenchment device. Finally, an increase in $c$ at most moves $D^{\star}$ from $\left[0, D^{*}\right]$ to $D^{\circ}$ implying an increase in the optimal debt.

- $\frac{\partial D}{\partial G(\theta)} \geq 0$. If $c<C_{D^{\circ}}$ then the optimal debt level is a riskless one, and at most the interval of optimal debt levels may increase. If $c>C_{D^{\circ}}$, then $D^{\star}=D^{\circ}$ and it is easy to see that $\frac{\partial D^{\circ}}{\partial G(\theta)}>0$. Only if $c=C_{D^{\circ}}$, we have the possibility that an increase increase in $G(s)$ decreases the optimal debt by moving $D^{\star}$ from $D^{o}$ to $\left[0, D^{s}\right]$.

\section{Proof of Corollary 2:}

The results follow from implicit differentiation of $\Delta S(D)=c$ in the four cases presented in Lemma 1. We present here the results for the second interval. The steps are the same in the other three. From Lemma 1 we know that $\frac{\partial \Delta S(D)}{\partial \theta_{D}}<0$. Therefore it follows that $\operatorname{sign}\left(\frac{d \theta_{D}}{d G(s)}\right)=\operatorname{sign}\left(\frac{d[\Delta S(D)-c]}{d G(\theta)}\right)$. However, $\frac{d[\Delta S(D)-c]}{d G(s)}=$ $\int_{\theta_{D}}^{1} d \theta+\int_{\theta_{D}-G}^{\frac{1}{1-\lambda}\left[\theta_{D}-G(\Delta)\right]} d \theta>0$. Similarly, $\operatorname{sign}\left(\frac{d \theta_{n}}{d c}\right)=\operatorname{sign}\left(\frac{d[\Delta S(D)-c]}{d c}\right)$. But $\frac{d[\Delta S(D)-c]}{d c}=-1<0$. Finally, $\operatorname{sign}\left(\frac{d \theta_{D}}{d \lambda}\right)=\operatorname{sign}\left(\frac{d[\Delta S(D)-c]}{d \lambda}\right)$ which equals (after some simplifications) to $\int_{\frac{1}{1-\lambda}\left[\theta_{D}-G\right]}^{\theta_{D}} \theta d \theta>0$.

\section{Proof of Corollary 3:}

Initial shareholders solve

$$
\max _{\theta_{D} \in[0,1]} V\left(\theta_{D}\right)+t B\left(\theta_{D}, t\right)
$$

where $V\left(\theta_{D}\right)$ is the firm's value net of the debt tax shield $t B\left(\theta_{D}, t\right)$ (which is given by the tax rate times the market value of the debt), and $\theta_{D}$ is the worst state in which the firm can fully pay a debt with face value $D$. To compute this worst state we solve $D=\theta_{D}+y_{2}(s)+t D \Rightarrow D=\frac{\theta_{D}+y_{2}(s)}{1-t}$. The debt tax shield for a debt 
with face value $D$ is then equal to

$$
\frac{t}{1-t}\left[\int_{0}^{\theta_{D}} \min \left\{(1-\lambda) \theta+G(s)+y_{2}(s), \theta_{D}+y_{2}(s)\right\} d \theta+\int_{\theta_{D}}^{1} \theta_{D}+y_{2}(s) d \theta\right] .
$$

Let's define

$$
\tilde{\theta}= \begin{cases}0 & \text { if }(1-\lambda) \theta+y_{2}\left(s^{\star}\right)>\theta_{D}+y_{2}(s) \forall \theta \\ \theta_{D} & \text { if }(1-\lambda) \theta+y_{2}\left(s^{\star}\right)<\theta_{D}+y_{2}(s) \forall \theta \\ \text { solves }(1-\lambda) \theta+y_{2}\left(s^{\star}\right)=\theta_{D}+y_{2}(s) & \text { otherwise. }\end{cases}
$$

Then, the debt tax shield can be rewritten as

$$
\operatorname{DTS}(D)=\frac{t}{1-t}\left[\int_{0}^{\bar{\theta}}\left[(1-\lambda) \theta+G(s)+y_{2}(s)\right] d \theta+\int_{\bar{\theta}}^{1}\left[\theta_{D}+y_{2}(s)\right] d \theta\right] .
$$

For $\theta_{D}<1, \frac{\theta D T S(D)}{d \theta p}=1-\tilde{\theta}$ is always positive. In particular, the derivative will be positive for $\tilde{\theta}=\theta_{D}=\frac{G}{\lambda}$, which is the initial shareholders' optimum in a world without taxes. Therefore, the introduction of a tax subsidy for debt will have the effect of increasing debt.

Proof of Lemma 4: We look for the debt level that maximizes firm's value. Any $D<\frac{y_{3}\left(e^{*}\right)}{1-t}$ cannot be optimal because the latter gives the highest tax saving among the riskless debt levels. Moreover, any debt level that implies bankruptcy with probability 1 induces the same value for the firm because the tax saving depends on the market value of debt, not on the face value. Therefore, we can restrict our attention to the following program

$$
\begin{gathered}
\max _{\left\{\theta_{D} \in[0,1]\right\}} \theta_{D}\left[E\left[(1-\lambda) \theta \mid \theta<\theta_{D}\right]+y_{2}\left(s^{\star}\right)+t\left(\frac{E\left[(1-\lambda) \theta \mid \theta<\theta_{D}\right]+y_{2}\left(s^{\star}\right)}{1-t}\right)\right]+ \\
\left(1-\theta_{D}\right)\left[E\left[\theta \mid \theta \geq \theta_{D}\right]+y_{2}\left(s^{\star}\right)+t\left(\frac{\theta_{D}+y_{2}\left(s^{\star}\right)}{1-t}\right)\right]
\end{gathered}
$$

Using $\theta_{D} E\left[\theta-\lambda \theta \mid \theta<\theta_{D}\right]=\int_{0}^{\theta_{D}}(\theta-\lambda \theta) d \theta$, and $\left(1-\theta_{D}\right) E\left[\theta \mid \theta \geq \theta_{D}\right]=\int_{\theta_{D}}^{1} \theta d \theta$, we can rewrite our program as

$$
\max _{\left\{\theta_{D}\right\}} E[\theta]+\frac{y_{2}\left(s^{\star}\right)}{1-t}+\frac{t}{1-t} \int_{0}^{\theta_{D}} \theta d \theta-\frac{\lambda \theta_{D}^{2}}{2(1-t)}+\left(1-\theta_{D}\right) \frac{t \theta_{D}}{1-t}, \text { s.t. } \theta_{D} \in[0,1] .
$$

Differentiating the objective function with respect to $\theta_{D}$, we obtain the first order condition (FOC) for an interior maximum:

$$
-\lambda \theta_{D^{T}}+t\left(1-\theta_{D^{T}}\right)=0 .
$$

The FOC is also sufficient. To see that $\theta_{D^{T}}$ increases with $t$, and decreases with $\lambda$, we use the implicit function theorem in the FOC

$$
\begin{gathered}
\frac{\partial \theta_{D^{T}}}{\partial \lambda}=\frac{\theta_{D^{T}}}{-(\lambda+t)}<0 . \\
\frac{\partial \theta_{D^{T}}}{\partial t}=\frac{-\left(1-\theta_{D^{T}}\right)}{-(\lambda+t)}>0 .
\end{gathered}
$$

\section{Proof of Proposition 4:}

Define $\Psi\left(t, \lambda, c, G(s), \theta_{D^{r}}\right) \equiv G(s)+R\left(t, \lambda, \theta_{D^{T}}, G(s)\right)-c$ as the takeover profit. By the envelope theorem, we can take $\theta_{D^{T}}$ as a constant when we differentiate $\Psi\left(t, \lambda, c, G(s), \theta_{D^{r}}\right)$. Therefore, we will simplify the 
notation by dropping $\theta_{D^{T}}$ as an argument of $\Psi$ and $R$. Now, consider the equation $G(s)+R(t, \lambda, G(s))=c$. By the Implicit Function Theorem, the above equation defines a continuously differentiable function $\tilde{t}(c, \lambda, G(s))$ if and only if $\frac{\theta \Psi(t, \lambda, c, G(s))}{\partial t} \neq 0$. Indeed,

$$
\frac{\partial \Psi(.)}{\partial t}=\frac{1}{(1-t)^{2}}\left[\int_{0}^{\theta_{D} T}(\theta-\lambda \theta) d \theta+\left(1-\theta_{D^{T}}\right)\left(\theta_{D^{T}}\right)+G(s)\right]>0
$$

Since $\frac{\partial \Psi(t, \lambda, c, G(s))}{\partial t}>0$ and $\Psi(\tilde{t}(c, \lambda, G(s)), \lambda, c, G(s))=0$, a takeover is not profitable for any $t<\tilde{t}(c, \lambda, G(s))$. Moreover, $t(c, \lambda, G(s))>0$, for $\Psi(0, \lambda, c, G(s))=G(s)-c<0$. To prove that $\tilde{t}(c, \lambda, G(s))<1$, note that $\Psi\left(t, \lambda, c, G(s), \theta_{D^{T}}\right)>G(s)+R(t, \lambda, 0, G(s))-c=G(s)+\frac{t G(s)}{1-t}-c$. Define, $\hat{t}=1-\frac{G(s)}{c}<1$. Thus, $G(s)+R(\hat{t}, \lambda, 0, G(s))-c=0$. It then follows that a takeover must be strictly profitable for a subsidy $t$ sufficiently close to $t$ when we take into account the additional profit from optimally levering up the company. Hence, $\tilde{t}(c, \lambda, G(s))<\hat{t}<1$. To do comparative statics on $\tilde{t}(c, \lambda, G(s))$ we use the Implicit Function Theorem on $\Psi(t, \lambda, c, G(s))$.

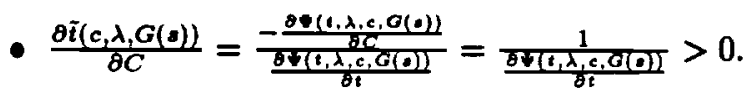

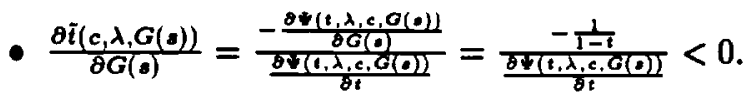

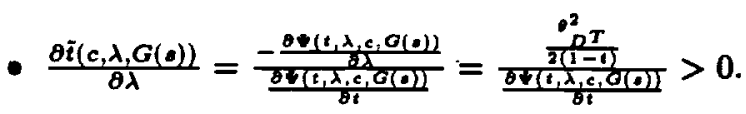

\section{Proof of Proposition 5:}

Let's first prove that, unlike in the case of the tax subisdy for debt, the tax subsidy for equity does not change the state of the world in which the company goes into bankruptcy. In a world without taxes, the cut-off state, $\theta_{0}$, for bankruptcy under a debt with face value $D$ solves $D=\theta_{0}+y_{2}(s)$. In a world with taxes the threshold for bankruptcy is defined by

$$
D=\theta+y_{2}(s)+t\left[\theta+y_{2}(s)-D\right] \Rightarrow(1+t) D=(1+t)\left(\theta+y_{2}(s)\right) \Rightarrow \theta=\theta_{0} .
$$

Now, call $\Delta S(D)$ the equity gain from a takeover when the face value of debt is $D$ and there are no taxes. Then, if we introduce a tax subsidy for equity we can write (thanks to the first part of the proof) the equity gain from a takeover as $\Delta S(D)+t \Delta S(D)$. But before the introduction of the tax subsidy for equity the manager chose the level of debt so that $\Delta S(D)=c$. Therefore, after the introduction of the tax subsidy the raider's profit will be equal to $c+t \Delta S(D)>c$. As a result, the manager, will be forced to set $\tilde{D}$ so that $(1+t) \Delta S(\tilde{D})=c$. Given that $\Delta S(D)$ decreases with $D$, we have $\tilde{D}>D$. 


\section{References}

Billett, M. 1995, "Targeting Capital Structure: The Relationship Between Risky Debt And The Firm's Likelihood of Being Acquired", Journal of Business forthcoming.

Burkart, M., D. Gromb, and F. Panunzi 1995, "Debt design, liquidation value and monitoring," mimeo London School of Economics.

Bolton P. And D. Scharfstein 1992, "Optimal Debt Structure with Multiple Creditors", MIT working paper.

Donaldson, G. 1961, Corporate Debt Capacity, Harvard University Press, Boston.

Donaldson, G. 1969, Strategy for Financial Mobility, Harvard University Press, Boston.

Graham, J. R. 1995, "Debt and Marginal Tax Rate," Journal of Financial Economics, forthcoming .

Gertler, M. And R. G. Hubbard 1990, "Taxation, Corporate Capital Structure, and Financial Distress", in L.H. Summers, ed. Tax Policy and The Economy, Cambridge, Mass.: MIT Press, 1990.

Gilson, S. AND J. Warner 1995, "Junk Bonds, Junk Theory, and Bank Debt," Harvard University, mimeo.

Grossman, S. and O. Hart 1980, "Takeovers Bids, the Free Rider Problem and the Theory of the Corporation", Bell Journal of Economics 11: 42-69.

Grossman, S. ANd O. Hart 1982, "Corporate Financial Structure and Managerial Incentives", in J. McCall The Economics of Information and Uncertainty

Grossman,S. and O. Hart. 1988, "One Share-One Vote and the Market for Corporate Control" Journal of Financial Economics 20: 175-202.

HaRris M. AND A. Raviv 1988, "Corporate Control Contests and Capital Structure", Journal of Financial Economics 20: 55-86.

Harris, M., A. Raviv 1989, "The Design of Securities" Journal of Financial Economics 24: 255-287.

Hart, O. and J. Moore 1995, "Debt and Seniority: An Analysis Of The Role of Hard Claims in Constraining Management", American Economic Review 85: 566-585.

IsRAEL, R. 1991, "Capital Structure and the Market for Corporate Control: The Defensive Role of Debt Financing", Journal of Finance, 46: 1391-1409.

IsRAEL, R. 1992, "Capital and Ownership Structures, and the Market for Corporate Control", Review of Financial Studies 5: 181-198. 
Jensen, M. 1986, "Agency Costs of Free Cash Flow, Corporate Finance, and Takeovers", American Economic Review, 76: 323 - 329.

JENSEN,M. AND K.J. MURPhy 1990, "Performance Pay and Top-Management Incentives" Journal of Political Economy 98: 225-264.

MACKIE-Mason, J. 1991, "Do Taxes Affect Corporate Financing Decisions", Journal of Finance, 45: 1471 - 1493.

MYers, S. 1984, "The Capital Structure Puzzle", Journal of Finance, 3: 575 - 592.

Mullins, D.W. JR. 1981, "American Home Products Corp." , Harvard Business School case, 9-283-065.

Novaes, W. AND L. Zingales 1995, "Financial Distress as a Collapse of Incentives", mimeo, University of Chicago, http://gsblgz.uchicago.edu

Opler, T. And Titman, S. 1995, "The Debt-Equity Choice," Boston College, mimeo.

Rajan, R. AND A. Winton 1995, "Debt Covenants, Collateral, and Delegated Monitoring," Journal of Finance forthcoming.

Rajan, R. And L. Zingales 1995, "What Do We Know About Capital Structure: Some Evidence From International Data" Journal of Finance forthcoming.

Shleifer, A. AND R. VishnY 1989, "Management Entrenchment: The Case of ManagerSpecific Assets," Journal of Financial Economics, vol.25: 123-140.

Shyam-Sunder, L. AND S.C. Myers 1993, "Testing Trade-Off Against Pecking Order Models of Capital Structure" mimeo.

StUlz, R. 1988 "Managerial Control of Voting Rights", Journal of Financial Economics 20: $25-54$.

Stulz, R. 1990 "Managerial Discretion and Optimal Financing Policies", Journal of Financial Economics 26: 3-27.

VISHNY, R. 1992, "Teachning Notes on the American Home Products Corp.", mimeo, University of Chicago.

ZWIEBEL, J. 1992, "A Control Theory of Dynamic Capital Structure", mimeo, Stanford GSB. 